\title{
Oestrogen and progesterone receptor assessment in core biopsy specimens of breast carcinoma
}

\author{
Amina Zidan, J S Christie Brown, D Peston, S Shousha
}

An abstract of this study was presented at the Summer Meeting of the Pathological Society of Great Britain and Ireland, held at Southampton, in July 1996

\begin{abstract}
Aims-To assess the suitability of core biopsy specimens for the immunohistological assessment of oestrogen and progesterone receptors in breast carcinoma. Methods-Thirty consecutive cases of clinically palpable breast carcinoma, from which both core and excision biopsy specimens were available, were examined. Routinely processed paraffin wax sections were stained using the specific monoclonal antibodies 1D5 (Dako) for oestrogen receptor and NCL-PGR (Novocastra) for progesterone receptor, after an antigen retrieval step using a pressure cooker. Staining results were assessed using the $H$ score system with the results being expressed as negative, weakly positive, moderately positive or strongly positive.

Results-Twenty six biopsy specimens contained enough tumour tissue for assessment. Absolute agreement between scoring categories was seen in $19(73 \%)$ cases for oestrogen receptors. However, when all positive categories were added together, agreement between core and excision biopsy specimens increased to 93\% ( 24 cases). Disagreement was seen only in two cases which stained positive in the core biopsy specimens and negative in the excision biopsy specimens. For progesterone receptors, the absolute agreement between all scoring categories was seen only in $11(42 \%)$ cases. When all positive categories were considered together, agreement increased to $69 \%$ (18 cases). Five cases were progesterone receptor positive in core but not in excisional biopsy specimens, while three cases were negative in core but positive in excisional biopsy specimens.
\end{abstract}

Conclusions-The results suggest that core biopsy specimens can be reliably used for oestrogen receptor assessment, but are less reliable for progesterone receptor assessment, probably because of a greater heterogeneity of progesterone receptor staining.

(F Clin Pathol 1997;50:27-29)

Keywords: breast carcinoma; core biopsy specimens oestrogen receptors; progesterone receptors.

Knowledge of the receptor content of breast carcinoma, particularly that of oestrogen receptors, is usually considered to be essential for planning the management of the disease..$^{12}$
Therefore, assessment of receptor content in routinely processed paraffin wax sections of excision biopsy specimens has now become well established and widely used, particularly after the introduction of new antibodies, and microwave and pressure cooker antigen retrieval techniques. ${ }^{3-5}$ In the meantime core biopsy specimens are increasingly being used for the preoperative diagnosis of breast carcinoma, and in some cases, such as advanced disease, a core biopsy specimen may be the only tissue sample available for diagnostic purposes before medical treatment is started. However, the reliability of using core biopsy specimens for detailed histological assessment is in doubt because of their relatively small size and the possible heterogeneity of the tumours. ${ }^{6}$ We carried out this retrospective investigation to study the reliability of using core biopsy specimens for the assessment of oestrogen and progesterone receptors in a consecutive series of breast carcinomas from which both core and excision biopsy specimens were available for examination.

\section{Methods}

Thirty consecutive cases of clinically palpable breast carcinomas from which both core and excision biopsy specimens were available from the same tumour, were examined. On average, excision biopsy specimens were taken within two weeks of establishing the diagnosis from the core biopsy. Both types of specimens were fixed in $10 \%$ neutral formalin. The number of cores in each core biopsy specimen varied between one and four, with a mean of 1.9 cores. These were fixed immediately after removal. Excision biopsy specimens were mostly sent fresh to our laboratory, where they were sampled and fixed in formalin within half an hour. Most core biopsy specimens, like other small biopsy specimens in our laboratory, were kept in the fixative for about three hours before routine processing overnight and embedding in paraffin wax the following day. On the other hand, excision biopsy samples, in general, were left in formalin overnight before processing on the following day, and embedded in paraffin wax the next day.

Sections, 3-4 $\mu \mathrm{m}$ thick, were cut, mounted on APES (Sigma, Poole, Dorset, UK) treated slides, and left to dry overnight at $37^{\circ} \mathrm{C}$. On the following day, sections were dewaxed in xylene and rehydrated in graded alcohol. Endogenous peroxidase was blocked using $2 \%$ hydrogen peroxide in methanol for 10 minutes. Sections 
Table 1 Correlation between oestrogen receptor staining in core and excision biopsy specimens

\begin{tabular}{llllll}
\hline Excision & +++ & ++ & + & - & Total \\
\hline Core & & & & & \\
+++ & 12 & 4 & 0 & 0 & 16 \\
++ & 1 & 4 & 0 & 1 & 6 \\
+ & 0 & 0 & 0 & 1 & 1 \\
- & 0 & 0 & 0 & 3 & 3 \\
Total & 13 & 8 & 0 & 5 & 26
\end{tabular}

were then placed in a stainless steel pressure cooker (Prestige 6185) containing $1400 \mathrm{ml}$ of boiling $10 \mathrm{mM}$ citrate buffer (pH 6.0). The lid was then locked and, once full pressure was reached, the sections were boiled for 90 seconds. The cooker was immediately placed under cold running tap water to release the pressure, the sections put directly into a bath of tap water, and then rinsed in TRIS-buffered saline (TBS). Normal horse serum, diluted 1 in 10, was applied for 20 minutes and then tipped off. The primary antibody was then applied for 60 minutes at room temperature. For oestrogen receptors, the monoclonal antibody 1D5 (Dako Ltd. High Wycombe, UK) was used at a concentration of 1 in 80 . For progesterone receptors, we used the monoclonal antibody NCL-PGR (Novocastra, Newcastle upon Tyne, UK) also at a concentration 1 in 80 . Sections were then rinsed in TBS, covered with the biotinylated secondary antibody, horse antimouse (Vector BA2000), diluted 1 in 300, for one hour, rinsed again in TBS and then covered by avidin-biotin complex (Vector Elite PK6100), 1 in 100 for 45 minutes. After rinsing in TBS, sections were incubated with $0.05 \%$ diaminobenzidine (Sigma) in PBS with $0.01 \%$ hydrogen peroxide added for five minutes, rinsed in tap water, counterstained with Harris' haematoxylin for one minute, blued in tap water, dehydrated, cleared and mounted. Positive controls comprised sections of oestrogen or progesterone receptor known positive breast carcinoma. Negative controls comprised sections of cases under examination, treated in the same way except that the primary antibody was omitted.

Staining results were assessed semiquantitatively using McCarty's $\mathrm{H}$ scoring system $^{7}$ where the percentage of stained cells is multiplied by a number, $0-3$, reflecting the intensity of their staining. This gives a total score varying from $0-300$ which is expressed as negative $(-, \mathrm{H}$ score 50 or less), weakly positive $(+, 51-100)$, moderately positive $(++, 101-$ $200)$ or strongly positive (+++, 201-300). Each set of biopsy specimens, core or excision, was assessed separately without knowing the result of the corresponding excision or core specimen.

\section{Results}

Four cases were excluded from the study because of the presence of only a few, less than 50 , tumour cells in the stained sections. The results of the remaining 26 cases are summarised in tables $1-4$.

For oestrogen receptors (table 1) (fig 1), absolute agreement between scoring categories was seen in $19(73 \%)$ cases. However, when all
Table 2 Cumulative correlations between oestrogen receptor staining in core $(C)$ and excision $(E)$ biopsy specimens

\begin{tabular}{ll}
\hline & $N=26(\%)$ \\
\hline $\mathrm{C}+/ \mathrm{E}+$ & $21(81)$ \\
$\mathrm{C}-/ \mathrm{E}-$ & $3(12)$ \\
$\mathrm{C}+/ \mathrm{E}-$ & $2(7)$ \\
$\mathrm{C}-/ \mathrm{E}+$ & 0
\end{tabular}

Table 3 Correlation between progesterone receptor staining in core and excision biopsy specimens

\begin{tabular}{llllll}
\hline Excision & +++ & ++ & + & - & Total \\
\hline Core & & & & & \\
+++ & 7 & 3 & 2 & 1 & 13 \\
++ & 2 & 0 & 0 & 2 & 4 \\
+ & 0 & 0 & 0 & 2 & 2 \\
- & 1 & 0 & 2 & 4 & 7 \\
Total & 10 & 3 & 4 & 9 & 26
\end{tabular}

Table 4 Cumulative correlations between progesterone staining in core $(C)$ and excision $(E)$ biopsy specimens

\begin{tabular}{ll}
\hline & $N=26(\%)$ \\
\hline $\mathrm{C}+/ \mathrm{E}+$ & $14(54)$ \\
$\mathrm{C}-/ \mathrm{E}-$ & $4(15)$ \\
$\mathrm{C}+/ \mathrm{E}-$ & $5(19)$ \\
$\mathrm{C}-/ \mathrm{E}+$ & $3(12)$ \\
\hline
\end{tabular}

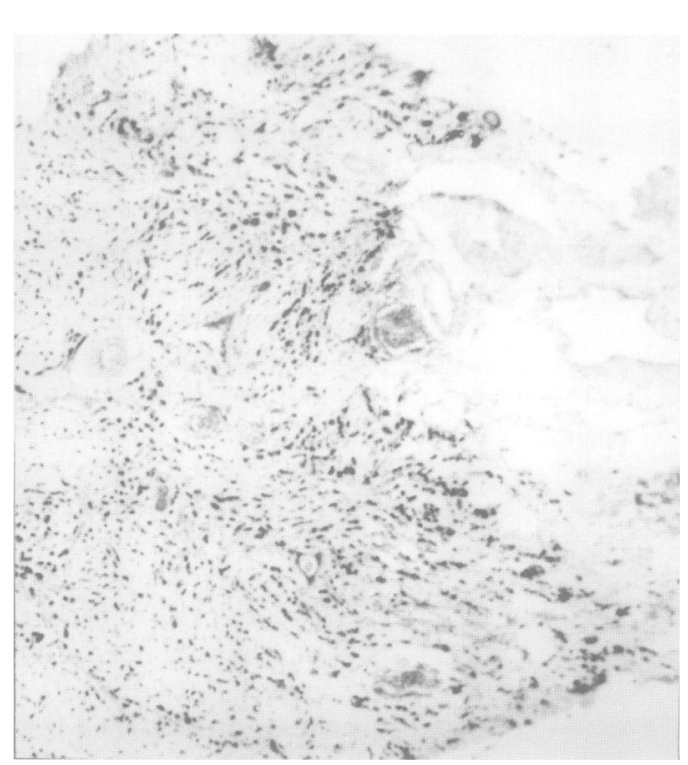

Figure 1 Breast core biopsy specimen showing oestrogen receptor positive invasive lobular carcinoma. (Immunoperoxidase stain.)

positive categories were considered together (table 2), agreement between core and excision biopsy specimens increased to $93 \%(24 / 26$ cases). Disagreement was seen only in two cases which stained positive in the core biopsy specimens (H scores 180 and 100 ) but negative in the excision biopsy specimens ( $\mathrm{H}$ scores 50 and 40 , respectively).

For progesterone receptors (table 3), the absolute agreement between all scoring categories was only seen in $11(42 \%)$ cases. Agreement increased to $69 \%$ (18/26 cases) when all positive cases were considered together (table 4). Five cases were progesterone receptor positive in the core biopsy specimens but negative in the corresponding excision biopsy specimens; three cases showed the opposite trend. 


\section{Discussion}

The results suggest that routinely processed breast core biopsy specimens containing reasonable numbers of tumour cells, can be reliably used for oestrogen receptor assessment. This may be particularly useful when administration of endocrine treatment is being considered before or instead of surgical excision of the tumour. ${ }^{8}$ In such a situation the only other alternative for establishing the receptor content of a tumour would be oestrogen receptor staining of cytological preparations obtained by fine needle aspiration. ${ }^{910}$ However, under these circumstances, a core biopsy specimen would have the advantage of permitting the differentiation between in situ and invasive cancers and of providing more accurate and detailed assessment of more tumours, including those of the invasive lobular type. ${ }^{11}{ }^{12}$ Although Pinder et al do not recommend the use of core biopsy specimens for grading invasive tumours, they accept that definitive treatment can be instituted, on the basis of a core biopsy specimen but not a fine needle aspirate, once invasive tumour has been seen in the former.

A $73 \%$ absolute agreement and a $93 \%$ partial agreement between oestrogen receptor scoring categories in the corresponding core and excision biopsy specimens is reasonably good, considering the difference in size between the two specimen types. This reflects our own experience that most tumours show a relatively homogenous staining for oestrogen receptors with the technique and antibody used in this study. This, however, is not always the case and variation in staining patterns is sometimes seen, particularly in tumours with extensive central fibrosis where tumour cells at the leading edge of the tumour can show much stronger staining than centrally located tumour cells. Whether this reflects an actual difference in oestrogen receptor content of tumour cells or an artefact related to better fixation and preservation of peripheral tumour cells, is difficult to know but would explain the much higher oestrogen receptor scores obtained in this study in two core biopsy specimens in spite of the low $\mathrm{H}$ scores of their corresponding excision biopsy specimens. For these two cases, there is also the added possibility that the stronger staining obtained in the core biopsy specimens is related to their prompt and better fixation because of their relatively small size. This possibility is supported by the fact that no oestrogen receptor negative core/positive excision biopsy specimens were encountered in this study.
However, assessment of progesterone receptor in core biopsy specimens seems to be less reliable with an absolute agreement of only $42 \%$ and a partial agreement of $69 \%$ between the scores of the two biopsy specimen types. This is probably a reflection of the greater heterogeneity of progesterone receptor expression which is commonly seen in stained sections of breast carcinoma, although the other factors discussed above in relation to oestrogen receptor may also have a role. The results, however, do not entirely invalidate the use of core biopsy specimens for progesterone receptor assessment, if they are the only source of tumour tissue available, but suggest a more cautious approach in their interpretation when clinical decisions are being made.

Dr Amina Zidan is Professor of Pathology at the Al-Azhar University, Cairo, Egypt. The study was carried out while she was a visiting Professor at the Department of Histopathology, Charing Cross and Westminster Medical School, London, during February and March 1996 . The study was partly supported by a grant from Dako Ltd., UK.

1 Low SC, Dixon AR, Bell J, Ellis IO, Elston CW, Robertson JFR, et al. Tumour oestrogen receptor content allows selection of elderly patients with breast cancer for conservative tion of elderly patients with breast cancer for con

2 Sacks NPM, Baum M. Primary management of carcinoma of the breast. Lancet 1993;342:1402-8.

3 Sannino P, Shousha S. Demonstration of oestrogen receptors in paraffin wax sections of breast carcinoma using the monoclonal antibody 1D5 and microwave oven processing. F Clin Pathol 1994;47:90-2.

4 Goulding $H$, Pinder S, Cannon P, Pearson D, Nicholson $R$ Snead D, et al. A new immunohistochemical antibody for the assessment of estrogen receptor status on routine formalin-fixed tissue samples. Hum Pathol 1995;26:291-4.

5 Goldberg DE, Stuart J, Koerner FC. Progesterone receptor detection in paraffin sections of human breast cancers by an immunoperoxidase technique incorporating microwave heating. Mod Pathol 1994;7:401-6.

6 Pinder SE, Elston CW, Ellis IO. The role of pre-operative diagnosis in breast cancer. Histopathology 1996;28:563-6.

7 McCarty KS Jr, Miller LS, Cox EB, Konarth J, McCarty KS Sr. Estrogen receptor analyses: correlation of biochemical and immunohistochemical methods using monoclonal antireceptor antibodies. Arch Pathol Lab Med 1985;109: 716-21

8 Powles TJ, Hickish TF, Makris A, Ashley SE, O'Brien MER, Tidy S, et al. Randomized trial of chemoendocrine therapy started before or after surgery for treatment of primary breast cancer. $\mathcal{f}$ Clin Oncol 1995;13:547-52.

9 Vielh P, Magdelenat H, Mosseri V, Remvikos Y, Di Bonito L. Immunocytochemical determination of estrogen and progesterone receptors on 50 fine-needle samples of breast cancer. A prospective study including biochemical correlation and DNA flow cytometric analysis. Am $\mathcal{F}$ Clin Pathol 1992;97:254-61.

10 Brotherick I, Shenton BK, Lennard TWJ. Are fine-needle breast aspirates representative of the underlying solid tumour? A comparison of receptor levels, ploidy and the influence of cytokeratin gates. Br f Cancer 1995;72:732-7.

11 Carty NJ, Ravichandran D, Carter C, Mudan S, Royle GT, Taylor I. Randomized comparison of fine-needle aspiration cytology and Biopty-Cut needle biopsy after unsatisfactory initial cytology of discrete breast lesions. $B r \mathcal{F}$ Surg 1994;81:1313-14.

12 Sadler GP, McGee S, Dallimore NS, Monypenny IJ, Douglas-Jones AG, Lyons K, et al. Role of fine-needle aspiration cytology and needle-core biopsy in the diagnosis of lobular carcinoma of the breast. Br $\mathcal{F}$ Surg 1994;81:1315-17. 